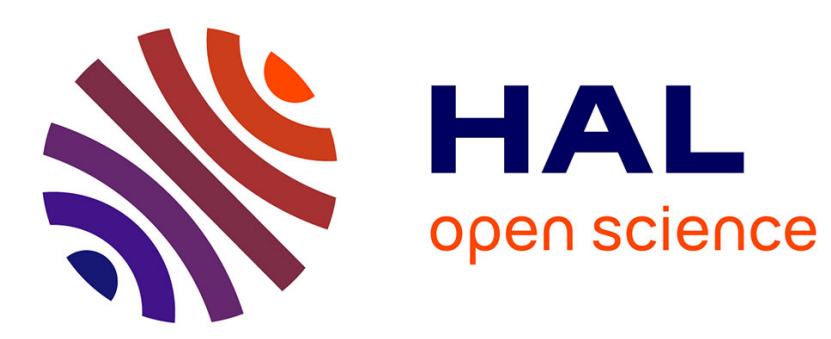

\title{
Direct quantification of O-atom in low-pressure methane flames by using two-photon LIF
}

\author{
Nathalie Lamoureux, Pascale Desgroux
}

\section{To cite this version:}

Nathalie Lamoureux, Pascale Desgroux. Direct quantification of O-atom in low-pressure methane flames by using two-photon LIF. Proceedings of the Combustion Institute, 2021, 38, pp.1753-1760. 10.1016/j.proci.2020.06.167 . hal-03008432

\section{HAL Id: hal-03008432 https://hal.science/hal-03008432}

Submitted on 11 Dec 2020

HAL is a multi-disciplinary open access archive for the deposit and dissemination of scientific research documents, whether they are published or not. The documents may come from teaching and research institutions in France or abroad, or from public or private research centers.
L'archive ouverte pluridisciplinaire HAL, est destinée au dépôt et à la diffusion de documents scientifiques de niveau recherche, publiés ou non, émanant des établissements d'enseignement et de recherche français ou étrangers, des laboratoires publics ou privés. 


\section{Direct quantification of O-atom in low-pressure methane flames by using two-photon LIF}

Nathalie Lamoureux* and Pascale Desgroux

\section{Affiliation}

Univ. Lille, CNRS, UMR 8522 - PC2A - Physicochimie des Processus de Combustion et de l'Atmosphère, F-59000 Lille, France

\section{Corresponding author:}

lab. PC2A, bat. C11, Cité scientifique, 59655 Villeneuve d'ascq, France,

nathalie.lamoureux@univ-lille.fr,

\section{Colloquium: DIAGNOSTICS}

Total: 6189 words (method 1, 6200)

Main text: 4518 words

References: $(32+2) * 2.3 * 7.6: 594$ words

3 Equations: $1 *(1+2) * 7.6+2 *(1+2) * 7.6 * 2: 114$ words

Table $1(5+2) * 7.6 * 1: 53$ words

Table $2(4+2) * 7.6 * 1$ : 46 words

Fig. 1. $(46.8+10) * 2.2+19: 144$ words

Fig. 2. $(48.4+10) * 2.2+22: 150$ words

Fig. 3. $(44.5+10) * 2.2+43: 163$ words

Fig. 4. $(45.5+10) * 2.2+16: 138$ words

Fig. 5. $(48.6+10) * 2.2+6: 134$ words

Fig. 6. $(49.3+10) * 2.2+17: 145$ words

SMM.pdf as Supplementary Materials 


\section{Abstract (276 words)}

Quantification of the O-atom concentration is particularly important for testing the detailed kinetic mechanisms in flames. In this work, relative concentrations of O-atoms are measured by using the two-photon Laser-Induced Fluorescence method (TPLIF). The direct calibration for determining the absolute O-atom mole fraction is achieved by comparing alternately the integrated TPLIF signals from the atomic oxygen and from a known quantity of a noble gas $(\mathrm{Xe})$. Both species have close spectral features with a two-photon absorption around 225 $\mathrm{nm}$, while the fluorescence signals are collected around 844 and $834 \mathrm{~nm}$ for O-atom and Xe, respectively. Application of this method previously adopted in plasma environments is demonstrated here for the first time in low-pressure hydrocarbon flames. One major achievement in this work is that the $\mathrm{O}$ and Xe fluorescence signals are measured in the flame, thus allowing to properly correcting for the quenching rate of both species in this high temperature environment. Due to the fast quenching rates of $\mathrm{O}$-atom and of $\mathrm{Xe}$ in the $\mathrm{N}_{2}$ diluted flames, a specific flame diluted in Ar was stabilized at $2.8 \mathrm{kPa}$ for the calibration procedure. From Stern-Volmer plots obtained in a large pressure range of flames, the quenching rate determination could be extended to nitrogen-diluted flames. Then, the O-atom profiles were measured in absolute mole fraction in three lowpressure $(5.3 \mathrm{kPa})$ premixed flames of $\mathrm{CH}_{4} / \mathrm{O}_{2} / \mathrm{N}_{2}$ with equivalence ratios equal to $0.8,1.0$ and 1.25 . The experimental profiles $\mathrm{O}$-atom mole fraction profiles are compared to the simulated ones. Their gradient locations and the absolute mole fractions at $25 \mathrm{~mm}$ are found in good agreement. However, the simulated profiles do not capture the experimental continuous decrease of $\mathrm{O}$ in the burnt gases

\section{Keywords:}

O-atom; Two-photon LIF; low-pressure flame; xenon; calibration 


\section{Introduction}

Quantitative knowledge of atomic $\mathrm{H}$ and $\mathrm{O}$ concentrations in flames is important for improving kinetic mechanisms in combustion. Indeed, atoms play a crucial role in combustion chemistry. However, the measurement of absolute concentration profiles of atomic species such as $\mathrm{O}$ and $\mathrm{H}$ still remains challenging.

Atomic species can be measured by using complex techniques such as Molecular Beam Mass Spectrometry (MBMS) after gas probe sampling [1], or by using in situ laser diagnostics such as Two-photon Laser-Induced Fluorescence (TPLIF). The conversion of relative fluorescence signals to absolute mole fraction is mostly performed through indirect approaches. Only Cheskis and Kovalenko [2] succeeded to quantify the O density in atmospheric $\mathrm{H}_{2}$ /air flames by using the very sensitive Intra Cavity Laser Spectroscopy absorption technique applied on O-atom forbidden transitions at 630 and $636 \mathrm{~nm}$.

The advantage of TPLIF is that it provides in situ detection of atomic species in flames. The method is very sensitive and gives access to the relative value of atom concentrations. Electronic states of O-atom lying at $88631 \mathrm{~cm}^{-1}$, they are excited by a two-photon process at $44315.5 \mathrm{~cm}^{-1}(225.65 \mathrm{~nm})$ to overcome the difficulties of working in the VUV range. Oxygen atoms have been measured with this method in low-pressures flames $[3,4]$ and in atmospheric flames [5-7].

Due to the use of high energy ns-lasers, photolytic or photochemical effects were observed, in particular with the production of $\mathrm{O}$ atoms stem from $\mathrm{CO}_{2}$ or $\mathrm{O}_{2}$ photolysis as described in [3-5,7] and in references herein. These effects are greatly attenuated by using ps-lasers or fs-lasers. Thus, there has been a renewed interest of TPLIF for measuring atomic oxygen in flames with short-duration laser pulses [8-10]. Moreover, the quenching can be measured from the temporal fluorescence decay in order to correct the LIF signal. However, this opportunity does not seem to have been explored in flames, but only in plasma [11]. One other effect contributing to the excited level depopulation is the stimulated emission (SE) under high laser intensity as reported in $[8,12-14]$.

The conversion of TPLIF signals into absolute atom concentrations requires the knowledge of different spectroscopic parameters (absorption cross section, radiative lifetime ...), and of the experimental parameters (quenching rate, laser fluence ...). As with any LIF method, this conversion requires the estimation of the 
volume of collection and the photon collection efficiency. So, indirect calibration was performed either by using Rayleigh scattering experiments [15], or by comparing the TPLIF signal measured in flames with the one collected from a known concentration of $\mathrm{O}$ atoms generated in a flow discharge tube at room temperature and the one measured in the flame [3]. Alternatively, the calibration can be done via comparing it with the estimated atomic oxygen concentration according to the partial equilibrium calculation [16], to adiabatic equilibrium $[9,17]$, or adiabatic flame simulation [10]. However, the drawbacks of the TPLIF quantification lie in the lack of knowledge of the quenching rates of the atomic species with the multi-colliders, which are present in the flame.

In 1998, Goehlich et al. [18] proposed a comparative calibration with a noble gas to determine the concentration of atomic species using TPLIF. Xenon exhibits two-photon resonance with excitation energies close to the oxygen ones. This approach was largely applied in the plasma community [11,19-22] where the absolute calibration of $\mathrm{O}$ atom is performed from xenon TPLIF excitation in a calibration cell at very low pressure [19-21], or in unpowered jet at atmospheric pressure [11,22]. In both cases, the calibration is performed in non-reactive mixtures.

To the best of our knowledge, the oxygen TPLIF signal has never been quantified in flames by using a noble gas. The present work aims to explore this promising way of quantifying the O-atom concentration. The method is applied in flames previously stabilized in our laboratory, in line with the establishment of the extensive database dedicated to the NO formation chemistry [23]. Indeed, the predicted NO (both from the thermal and the prompt routes) is very sensitive to the trace species, including the atomic species. The absolute calibration of the O-atom required a well-defined calibration flame where the O-TPLIF signal was directly correlated with the one emitted from the noble gas $(\mathrm{Xe})$. In order to convert the relative signal into absolute mole fractions, attention was paid on the absence of interfering effects, and on the control of the quenching along the vertical axis of the flame. The experimental atomic oxygen profiles were compared with the simulated ones by using the Chemkin codes [24] with the detailed kinetic model developed in our laboratory [23]. 


\section{Experimental set-up}

\subsection{Low-pressure burner and gas supply}

Experiments were undertaken in laminar low-pressure methane flames stabilized on a 6-cm diameter bronze water-cooled McKenna burner. The temperature of the porous burner was stabilized at $293 \mathrm{~K}$ and $333 \mathrm{~K}$ for $\mathrm{N}_{2}$ and Ar diluted flames, respectively. The pressure regulation was achieved within $\pm 0.3 \%$ by using an automatic valve (Oerlikon CMOVE/MOVE1250). The burner was mobile in translation in the vertical axis allowing measuring species profiles as function of the height above the burner (HAB). Details about the burner and the gas supply are given in [25]. The volumetric gas flow rates of the studied flames were controlled with mass flow controllers (MFC) as reported in Table 1. The premixed flames of $\mathrm{CH}_{4} / \mathrm{O}_{2}$ diluted in $\mathrm{N}_{2}$ stabilized at 40 Torr $(5.3 \mathrm{kPa})$ were identical to those reported in $[23,25]$. The choice of the calibration flame diluted in $\mathrm{Ar}$ (named flame CH4_cal) is explained below (see §3.2.2). Xenon gas (Messer, purity 99.999\%) used for calibration purpose was introduced into the mixture gas line and controlled with a MFC (30 sccm, Bronkhorst, $\pm 0.5 \%$ ). Temperature profiles were already measured in the previously stabilized flames by using NO-LIF thermometry [23]. In the calibration flame, the temperature profile was determined according to the experimental approach described in $[25,26]$

Table 1. Flame compositions. Gas flow rates are reported in slpm (at $273.15 \mathrm{~K}$ and $101.3 \mathrm{kPa}$ ), (accuracy $\pm 2 \%$ ). $\phi$ is the equivalence ratio.

\begin{tabular}{|l|l|l|l|l|}
\hline Flame & $\mathrm{CH} 4$ & $\mathrm{O}_{2}$ & $\mathrm{~N}_{2}$ or $\mathrm{Ar}$ & $\phi$ \\
\hline CH4(080) & 0.384 & 0.96 & 3.20 & 0.80 \\
\hline CH4(100) & 0.48 & 0.96 & 3.35 & 1.00 \\
\hline CH4(125) & 0.60 & 0.96 & 3.29 & 1.25 \\
\hline CH4_cal & 0.36 & 0.72 & 2.95 & 1.00 \\
\hline
\end{tabular}

\subsection{Laser set-up}

The pulsed laser system consists of a frequency-doubled Nd:YAG laser (Powerlite DLS8000, Continuum) pumping a dye laser (ND6000, Continuum) providing $572 \mathrm{~nm}$ radiation. Wavelength around $226 \mathrm{~nm}$ was generated by mixing the residual IR of the YAG laser with the frequency doubled of the dye laser. The laser spectral bandwidth was measured to be around $1 \mathrm{~cm}^{-1}$. Typically, the output laser energy was equal to 700 
$\mu \mathrm{J} /$ pulse and attenuated with a variable attenuator consisting in a polarizer at $225 \mathrm{~nm}$ and a half-wave plate (EKSMA). The laser beam was focused with a $500 \mathrm{~mm}$ focal length lens and introduced parallel to the burner surface. Following [21], the lens was slightly moved to shift the beam waist away from the vertical burner axis, ensuring both a sufficient laser energy density and a reduced modification of the section of the volume along the laser axis. The laser intensity was monitored before the lens with an energysensor (J-10MB-HE, Coherent) The LIF signal was collected at $f / 4$ by a two-achromatic lenses system $(f=200 \mathrm{~mm}, 650-1050 \mathrm{~nm})$ and focused on the entrance slit of a $0.300 \mathrm{~m}$ spectrometer (SP2300i, ActonResearch) with a $150 \mathrm{gr} / \mathrm{mm}$ grating blazed at $500 \mathrm{~nm}$. The entrance slit $(250 \mu \mathrm{m}$ width, $8 \mathrm{~mm}$ height) was parallel to the laser axis. The spectrometer has a dual-exit; the side-exit was coupled with a 16-bit ICCD camera (PI-MAX 2, Roper Scientific), and the frontexit was coupled with a photomultiplier tube (PMT).

Temporal LIF signals were collected by a PMT (R2257, 2.6 ns rise time, Hamamatsu) and recorded on a digital oscilloscope (HDO4000, 12-bit vertical resolution, $1 \mathrm{GHz}$ bandwidth, $1.25 \mathrm{GS} / \mathrm{s}$, Lecroy). The LIF signals and the dye laser wavelength were processed and stored simultaneously using a Labview program to provide the LIF intensity, the laser intensity and the fluorescence lifetime in real time. The efficiency of the LIF collection systems was spectrally measured by using a uniform radiance calibrated source (CSTM-LR-6-M, SphereOptics).

Fluorescence spectra were collected from 200 to $900 \mathrm{~nm}$ by using the ICCD camera with a gate width of 150 ns. For that purpose and for the thermometry LIF, the achromatic lenses were substituted with fused silica lenses. Details about the thermometry setup are given in $[25,26]$.

SE was detected at the fluorescence transitions $(845$ and $835 \mathrm{~nm}$ ) by a fast photodiode (DET10A02, Thorlabs) (see $§ 3.2 .3$ ). A BK7 glass and a high-pass filter at $820 \mathrm{~nm}$ rejected the $226 \mathrm{~nm}$ light, similar to [10].

\section{Principle and experimental approach}

The calibration of TPLIF signal by using a noble gas was first proposed by Goehlich et al. [18]. Thanks to the similarity between the electronic states of $\mathrm{Xe}$ and $\mathrm{O}$-atom, and knowing the concentration of $\mathrm{Xe}$, the ratio of the 
TPLIF signals between $\mathrm{Xe}$ and $\mathrm{O}$ allows a direct calibration of the $\mathrm{O}$-atom concentration, provided that some precautions are undertaken as described below.

\subsection{Measurement of 0 and Xe by TPLIF}

Both species exhibit close excitation/collection energies diagrams as shown in Fig. 1. Atomic oxygen in the sub-level $(\mathrm{J} "=2)$ of the ground state is excited by two-photon absorption at $225.65 \mathrm{~nm}$ via the transition $3 \mathrm{p}{ }^{3} \mathrm{P}_{0,1,2} \leftarrow 2 \mathrm{p}^{4}{ }^{3} \mathrm{P}_{2}$ and the fluorescence signal is detected along the transition $3 \mathrm{p}{ }^{3} \mathrm{P}_{0,1,2} \rightarrow 3 \mathrm{~s}{ }^{3} \mathrm{~S}_{0}$ at $844.9 \mathrm{~nm}$ Initially, Goehlich et al. [18] proposed to excite Xe to the level $7 \mathrm{p}[3 / 2]_{2}\left(88687 \mathrm{~cm}^{-1}\right)$ with 2 photons at 225.51 $\mathrm{nm}$ followed by a fluorescence collection at $462.5 \mathrm{~nm}$. Due to the large difference in the collection wavelengths (845/462), a second scheme of Xe was later preferred [19]. Xe is excited with the two-photon resonance at $224.31 \mathrm{~nm}$ via the transition $6 \mathrm{p}^{\prime}[3 / 2]_{2} \leftarrow 5 \mathrm{p}^{6}{ }^{1} \mathrm{~S}_{0}$ and the fluorescence is collected at $834.9 \mathrm{~nm}$ along the transition $6 p^{\prime}[3 / 2]_{2} \rightarrow 6 s^{\prime}[1 / 2]_{1}$

Xe can easily be injected in a known amount in the premixed gases by substituting it for the diluent. The wavelengths used either to excite or to collect the fluorescence from both atoms $\mathrm{O}$ and Xe are close, this allows easy alternate measurements.

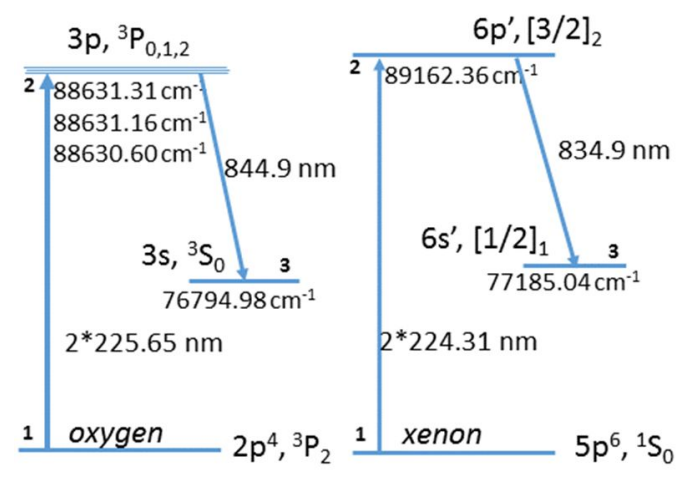

Fig. 1. TPLIF excitation and collection schemes of atomic $\mathrm{O}$ and Xe, from NIST [27]. The transition wavelengths are in vacuum.

Both species can be excited by using a two-photon process. According to [18,28], the time-integrated TPLIF signal collected by the PMT $\left(S_{i}\right)$ can be expressed as follows: 


$$
S_{i}=C_{i} \sigma_{i}^{\langle 2\rangle} g\left(\Delta \bar{v}_{i}\right) G^{\langle 2\rangle} \frac{A_{23, i}}{A_{i}+Q_{i}} f_{B}(T)[i]\left(\frac{I_{v_{i}}}{h v_{i}}\right)^{2}
$$

where $C_{i}$ is the global efficiency of the LIF collection at a given wavelength (PMT, spectrometer, lenses, solid angle, volume of measure), $\sigma_{i}^{\langle 2\rangle}$ is the lineshape-independent two-photon absorption cross section, $g\left(\Delta \bar{v}_{i}\right)$ is the normalized line profile of the two-photon excitation which is composed of the convolution of the effective laser line profile and the atomic absorption line, $G^{\langle 2\rangle}$ is the photon statistical factor $(=2), A_{23, i}$ is the spontaneous emission rate along the detection transition (from level 2 to 3), $A_{i}$ is the radiative lifetime of the excited level, $Q_{i}$ is the total quenching rate, and $[i]$ is the concentration of the species $i . f_{B}$ is the temperature-dependent Boltzmann function of the probed sub-level of the ground state. The ratio $I_{v_{i}} / h v_{i}$ represents the number of photons per time unit at a given frequency $v_{i}$, where $I_{v_{i}}$ is the laser intensity. Subscript " $i$ " indicates the species, either Xe or O.

\subsection{Calibration procedure}

\subsubsection{General aspects}

The procedure consists in comparing the TPLIF signals of $\mathrm{O}$ and Xe collected in a calibration flame seeded with a known mole fraction of xenon $\left(\chi_{X e}\right)$. According to [18-20], the atomic oxygen mole fraction $\left(\chi_{O}\right)$ is calculated from Eq. (2):

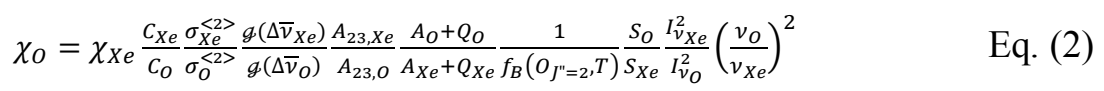

The spontaneous emission from the excited level of O-atom results in a unique transition, contrary to Xe, for which other transitions can occur. The one collected at $834 \mathrm{~nm}$ represents $73.3 \%$ of the total radiative emissions from the level 6p' (Xe) [20,29]. The fluorescence signal was captured with a bandwidth of $10 \mathrm{~nm}$ to ensure the collection of the entire selected transition. The atomic oxygen in the ground state ${ }^{3} \mathrm{P}$ is distributed into 3 sub-levels $(\mathrm{J}=0,1,2)$. The Boltzmann function of the probed sub-level $(\mathrm{J} "=2)$ is close to 0.6 at temperatures higher than $1300 \mathrm{~K}[20]$. Xenon in the ground state lies in a singlet state ${ }^{1} \mathrm{~S}$, and $f_{B}$ is equal to 1 , independent of the temperature. The adopted spectroscopic parameters are reported in Table 2. 


\begin{tabular}{|l|c|c|}
\hline & O & $\mathrm{Xe}$ \\
\hline$\sigma_{X e}^{<2>} / \sigma_{O}^{<2>}$ & \multicolumn{2}{|c|}{$1.9 \pm 20 \%[20]$} \\
\hline $1 / \mathrm{A}(\mathrm{ns})$ & $35.4[11]$ & $40.0[11]$ \\
\hline $\mathrm{A}_{23} / \mathrm{A}$ & $1[20]$ & $0.733[20,29]$ \\
\hline
\end{tabular}

The difficulty of the calibration procedure lies in the evaluation of the quenching rate of both atoms $(\mathrm{O}$ and Xe). It is defined by $Q_{i}=\sum_{n}[n] k_{n}^{i}$ where [n] is the concentration of the collider $\mathrm{n}$ and $k_{n}^{i}$ is the quenching coefficient. The quenching rate could be estimated from the concentration species profiles of the main colliders as simulated by using the Chemkin codes [24]. However, in the literature, the quenching coefficients are mostly reported at room temperature for O-atom with major flame species [4,30,31]. No data were found for Xe with the main products of the flame except for $\mathrm{CO}$ [32]. Therefore, the large inaccuracy may affect the theoretical calculation. Here, we have preferred to measure the quenching rate from the temporal fluorescence decay rate, whenever it is possible. This was the keystone for choosing the calibration flame.

\subsubsection{Selection of a calibration flame}

As described below, we have succeeded to measure the quenching rate of $\mathrm{O}$-atom in the investigated flames diluted in $\mathrm{N}_{2}$ because the quenching rate is relatively weak at low pressure. However, it turned out that the quenching rate of $\mathrm{Xe}$ was higher than that of $\mathrm{O}$-atom, in opposite with room temperature quenching coefficient values $[11,30]$. This led us to choose a calibration flame, in which the quenching rate was low enough to achieve its experimental measurement for both atomic species.

The fluorescence decaytime $\left(\tau_{f l}\right)$, defined by the inverse of the decay rate $\left(A_{i}+Q_{i}\right)$, was measured from the temporal LIF signal after the laser pulse. By plotting the measured decay rates as function of the pressure (for a given gas composition), one expects a straight line in the so-called Stern-Volmer plot. The extrapolation at zero-pressure fits well the radiative lifetime $\left(A_{i}\right)$. Deviation from the linearity at short $\tau_{f l}$ indicates that the laser pulse influence is no longer negligible. 
In the present work, $\tau_{f l}$ was measured from an exponential fitting between $90 \%$ and $20 \%$ of the normalized temporal LIF signal, and converted in A+Q.

Firstly, $\left(A_{i}+Q_{i}\right)$ of Xe was measured at room temperature under controlled mixture dilution in $\mathrm{N}_{2}$ and in Ar with $90 \mu \mathrm{J}$ per laser pulse. In $\mathrm{Ar},\left(A_{i}+Q_{i}\right)$ follows a linear increase from $2.5 \times 10^{7} \mathrm{~s}^{-1}$ (i.e. the radiative lifetime) up to $14 \times 10^{7} \mathrm{~s}^{-1}$ at $5.3 \mathrm{kPa}$, as shown in Fig. 2. On the contrary, in $\mathrm{N}_{2}$, the linearity is only observed up to $1 \mathrm{kPa}$ until $\left(A_{i}+Q_{i}\right)$ reaches a limit value of $16 \times 10^{7} \mathrm{~s}^{-1}$ (i.e. $\left.\tau_{f l}=6.25 \mathrm{~ns}\right)$. Note that the quenching rate of Xe in Ar was found approximatively 6 times lower than in $\mathrm{N}_{2}$ (see Fig. 2), while it was expected to be a factor of 3 according to the values reported in [11,22].

The exponential fitting method was compared with the approach followed in [21] which consists to perform the convolution of the squared laser pulse with an exponential decay. Illustration of the two approaches is given in Fig. S0. Both methods were found consistent within $4 \%$ in our conditions and led to an upper limit for $\left(A_{i}+Q_{i}\right)$ determination of $16 \times 10^{7} \mathrm{~s}^{-1}$ with an accuracy estimated to be equal to $\pm 5 \%$. This upper value is slightly above the value reported in [11].

Secondly, $\left(A_{i}+Q_{i}\right)$ was measured in various conditions of flames diluted in Ar with approx. 1\% of Xe. The calibration flame was selected by considering the best compromise between its flatness and stability, and the accessible quenching rate measurement of Xe. Finally, a stoichiometric $\mathrm{CH}_{4} / \mathrm{O}_{2}$ flame diluted with $73 \%$ Ar (flame CH4_cal) was stabilized at 21 Torr $(2.8 \mathrm{kPa})$ for the calibration purpose. In the burned gases of this flame (assuming a constant composition and temperature), the measured LIF decay rate follows a linear fitting from 2.1 to $2.8 \mathrm{kPa}$ as shown in Fig. 2. Measurements performed in $\mathrm{H}_{2} / \mathrm{O}_{2} / \mathrm{Ar}$ flames indicate that Xe was even quenched faster than in $\mathrm{CH}_{4} / \mathrm{O}_{2} / \mathrm{Ar}$ flames, confirming that $\mathrm{H}_{2} \mathrm{O}$ is a very efficient collider, compared to $\mathrm{CO}$ and $\mathrm{CO}_{2}[30]$. 


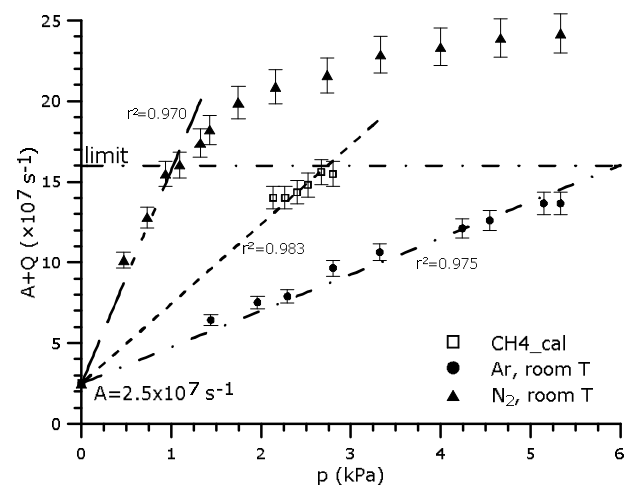

Fig. 2. Stern-Volmer plot for Xe at room temperature and in the burned gases of flame CH4_cal. Coefficient of linear regression $\left(\mathrm{r}^{2}\right)$ are indicated.

\subsubsection{Quadratic LIF regime}

The validity of Eq. (2) requires that the TPLIF signal follows a quadratic LIF regime. Figure 3 shows in a log$\log$ graph the TPLIF signal measured as function of the laser intensity. The linear slope of 2 ascertains the respect of the quadratic LIF regime. The deviation of this slope may indicate the presence of photolytic or photochemical effects, or the activation of photoionization [3], or SE [8]. Absence of these interfering effects can also be controlled by comparing the O-atom profiles obtained at different laser intensity $[4,5,8,11]$ (Fig. S1), and by checking the fluorescence spectra over a wide range of wavelengths (Fig. S2) [4]. The quadratic LIF regime is confirmed up to $300 \mu \mathrm{J} /$ pulse and $100 \mu \mathrm{J} /$ pulse for O-atoms and Xe, respectively (Fig. 3). The threshold of the SE onset for Xe is lower than the one of $\mathrm{O}$, and nearly coincides with the sub-linearity of the TPLIF regime (Fig. S3). As SE also depends on the species density [14], we have controlled firstly, that the Xe TPLIF signal strictly increased linearly with the $\mathrm{N}_{2}$ substitution by Xe (Fig. S4), and secondly, that the threshold of SE was higher than $250 \mu \mathrm{J} /$ pulse along the vertical axis of flame $\mathrm{CH} 4(080)$.

Measurements were performed at $100 \mu \mathrm{J} /$ pulse during all the calibration procedures, and at $150 \mu \mathrm{J} / \mathrm{pulse}$ for the measurements of the atomic oxygen profiles in $\mathrm{N}_{2}$-diluted flames. So, the laser intensity was low enough to ensure that the photolytic effect and SE are negligible. 


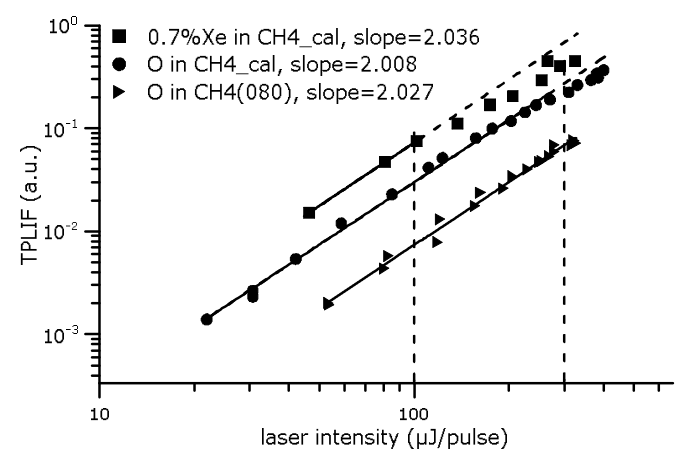

Fig. 3. TPLIF quadratic regime for $\mathrm{O}$ and $\mathrm{Xe}$. Solid lines represent the limit in which the quadratic regime is verified, and the dashed lines are extrapolated from the linear fit. For clarity, the TPLIF signal of O-atom in flame CH4 cal is divided by 2 .

\section{Results and discussions}

\subsection{Quantification of TPLIF in the calibration flame}

The implementation of the calibration procedure requires that the normalized line profiles be known for Xe and O-atom (Eq. (2)). In the present work, even if they are dominated by the laser bandwidth $\left(1 \mathrm{~cm}^{-1}\right)$, the linewidths of $\mathrm{Xe}$ and $\mathrm{O}$-atom were found different to the Doppler broadening (respectively equal to 0.24 and $0.66 \mathrm{~cm}^{-1}$ ) (Fig. S5). Therefore, following Goehlich et al. [18], the fluorescence signal was spectrally integrated over the absorption line of each species. So, the O-atom quantification was achieved by measuring alternately the time and spectrally integrated TPLIF signals from $\mathrm{O}$ and $\mathrm{Xe}$ in the burned gases $(\mathrm{HAB}=30 \mathrm{~mm})$ in flame $\mathrm{CH} 4$ cal. The flame was seeded with $0.8 \%$ Xe (in mole fraction) during Xe-TPLIF measurement. The laser intensity was maintained constant $(100 \mu \mathrm{J} /$ pulse $)$ at each excitation wavelength while the collection wavelength of the spectrometer was tuned appropriately.

The ratio of the collection efficiencies $\left(C_{X e} / C_{O}\right)$ at the two wavelengths (834 and $\left.845 \mathrm{~nm}\right)$ was determined to be equal to 1.6 (mainly due to the variation of the PMT spectral response) by using the calibrated source. At $\mathrm{HAB}=30 \mathrm{~mm}$, the fluorescence decay rate of $\mathrm{O}$-atom was measured to be equal to $6.5 \times 10^{7} \mathrm{~s}^{-1}$, i.e 2.5 times lower than that of Xe in flame $\mathrm{CH} 4$ cal. Figure 4 shows that it remains nearly constant from 10 to 35 $\mathrm{mm}$ (within 4\%), i.e. shortly from the O profile onset to the burnt gases. Using NO-LIF thermometry, the temperature profile was measured in the calibration flame along the HAB (Fig. 4). At HAB $=30$ mm, T=1955 
$\mathrm{K}$ leads to $f_{\mathrm{B}}=0.587$. Considering the spectroscopic parameters (Table 2), the mole fraction of the atomic oxygen was calculated to be equal to $1.2 \%$ at $\mathrm{HAB}=30 \mathrm{~mm}$, according to Eq. (2). The accuracy was estimated to be equal to $\pm 40 \%$, considering the standard deviations of the measurements $(6 \%)$, the ratio of the fluorescence decay rates $(10 \%)$, the accuracy of the Xe mole fraction $(2 \%)$ and the ratio of the two-photon absorption cross section $( \pm 20 \%)[20]$

As the temperature-dependency of the Doppler broadening of O-atom was found to be negligible from 10 to $35 \mathrm{~mm}$ in comparison with the laser linewidth, the O-atom profile was measured in relative mole fraction using the temporal peak of the LIF signal as function of the HAB. Finally, it was corrected for the Boltzmann function and temperature before being converted to absolute mole fraction as shown in Fig. 4.

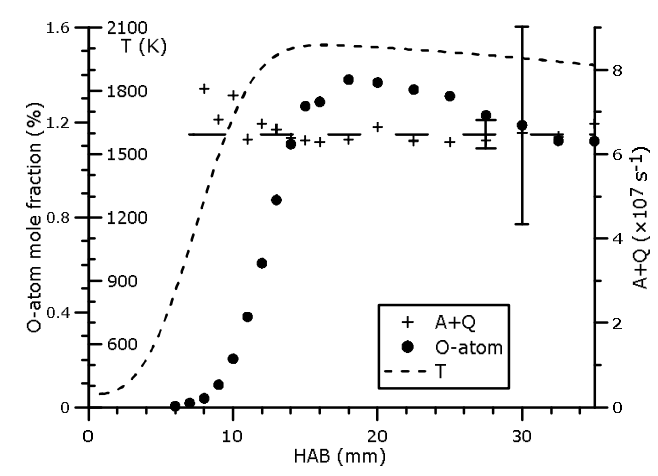

Fig. 4. O-atom mole fraction, temperature and fluorescence decay rate $(\mathrm{A}+\mathrm{Q})$ profiles along the $\mathrm{HAB}$ of flame $\mathrm{CH} 4$ cal.

\subsection{0 -atom mole fraction profiles in the $\mathrm{N}_{2}$ diluted flames}

Similarly, the time and spectrally integrated O-TPLIF signal was alternately measured in the 3 flames diluted in $\mathrm{N}_{2}$ and in flame $\mathrm{CH}_{4}$ _cal at $\mathrm{HAB}=20 \mathrm{~mm}$. Knowing the absolute mole fraction of the atomic oxygen in flame $\mathrm{CH} 4$ cal $\left(\chi_{o, c a l}=1.4 \%\right.$ at $\left.20 \mathrm{~mm}\right)$, the absolute mole fractions of O-atom were determined in all flames according to:

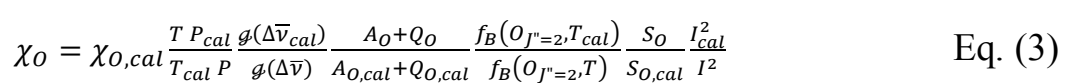


where $\mathrm{T}$ and $\mathrm{P}$ are the temperature and pressure in the flames. The subscript cal refers to the calibration flame. The Boltzmann function was calculated according to the temperature in each flames at $20 \mathrm{~mm}$ [23]. The laser fluence was thoroughly controlled to be equal to $100 \mu \mathrm{J} /$ pulse.

The Stern-Volmer plots for the O-atom were drawn in the investigated flames diluted in $\mathrm{N}_{2}$, Fig. 5. In flame $\mathrm{CH} 4$ cal, $\left(A_{i}+Q_{i}\right)$ follows a linear increase with the pressure up to $5.3 \mathrm{kPa}$ as for $\mathrm{Xe}$, far below the limit $\left(16 \times 10^{7} \mathrm{~s}^{-1}\right)$ defined in $\$ 3.2 .2$. On the contrary, in the $\mathrm{N}_{2}$ diluted flames, the decay rate (found independent of the flame richness) reaches this limit at around $4.25 \mathrm{kPa}$, and leads to the underestimated $\left(A_{i}+Q_{i}\right)$ at higher pressures. Assuming that the temperature and the composition of the flame were constant with the pressure increase, the quenching rate at $5.3 \mathrm{kPa}$ was determined from the linear extrapolation of the Stern-Volmer graph (Fig. 5). Therefore, in the studied $\mathrm{N}_{2}$ diluted flames, the fluorescence decay rate was estimated to be equal to $18.7 \times 10^{7} \mathrm{~s}^{-1}$, which is only $16 \%$ above the limit. In the calibration flame maintained at lower pressure $(2.8 \mathrm{kPa})$ and with Ar dilution, it was found equal to $6.5 \times 10^{7} \mathrm{~s}^{-1}$.

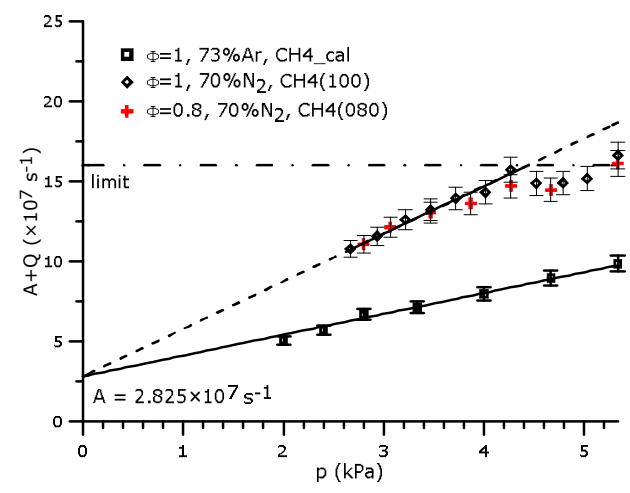

Fig. 5. Stern-Volmer plot for O-atom in flames.

The relative O-atom profiles were measured from the peak temporal O-TPLIF signal corrected for the laser intensity fluctuations $(150 \mu \mathrm{J} /$ pulse $\pm 5 \%), f_{B}$ and T along the HAB. $\left(A_{i}+Q_{i}\right)$ was assumed to be constant along the $\mathrm{HAB}$ as found in flame $\mathrm{CH}_{4}$ cal (Fig. 4). Figure 6 shows the experimental profiles of O-atom in absolute mole fraction after the conversion using Eq. (3) are plotted in Fig. 6. Finally, the absolute O-atom mole fraction was determined with an overall uncertainty of $45 \%$, considering the standard deviation of the last step consisting in the time- and spectrally-integrated TPLIF measurements between all flames. The most important 
factor of this large error bar is due to the uncertainty in the ratio of the two-photon absorption cross section $( \pm 20 \%)$ reported in [20]. It has been measured only once, by comparing the TPLIF measurements from known concentrations of $\mathrm{Xe}$ and $\mathrm{O}$ in a flow-tube apparatus at $1 \mathrm{kPa}$ and $300 \mathrm{~K}$. However, the relative uncertainty between the flames is only $25 \%$.

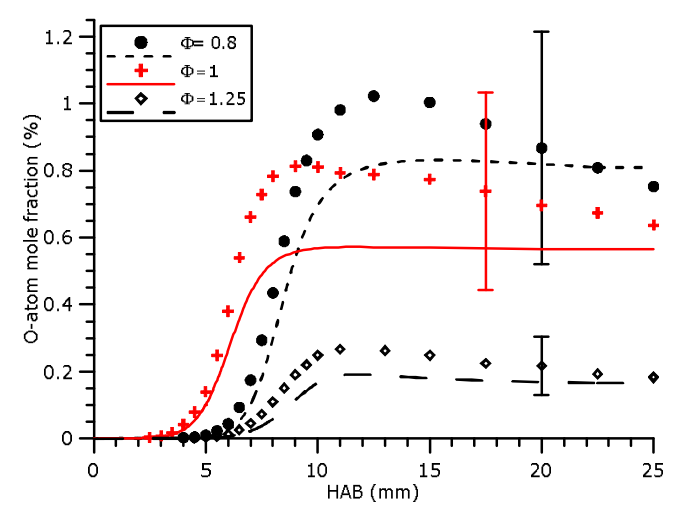

Fig. 6. O-atom mole fraction profiles in flames diluted with $\mathrm{N}_{2}$. Symbols: experimental points, lines: simulated with NOMecha2.0 [23]

Figure 6 shows the comparison between the experimental O-atom profiles and the simulated ones using NOMecha2.0 mechanism [23]. Considering the experimental uncertainties, an overall good agreement is observed. The onset and gradients of the $\mathrm{O}$ profiles are very well predicted. At $25 \mathrm{~mm}$ and for the 3 equivalence ratios, the agreement between the measured and the simulated mole fractions is found to be better than $5 \%$ as illustrated in Fig. S6. Note that in the present work, the calibration is directly performed from the comparison between the TPLIF signals from Xe and $\mathrm{O}$, but not from the relative comparison between the O-TPLIF signal and the simulated mole fractions as reported in $[9,10,17]$. In any case, the TPLIF was not corrected for the quenching variation as function of the equivalence ratio. Figure 6 shows that the model fails to reproduce the shape of the experimental profiles with a hump followed by a slight decrease in the burned gases. O-atom profiles in hydrocarbon flames have rarely been measured. The O-TPLIF profile measured in an atmospheric $\mathrm{CH}_{4} / \mathrm{O}_{2} / \mathrm{N}_{2}$ Bunsen flame was calibrated at its peak value from an adiabatic flame calculation in [10]. But the comparison in the burned gases reveals that the simulated $\mathrm{O}$ density lies $18 \%$ above the experimental one. Otherwise, the experimental signals obtained in various equivalence ratios were compared to 0-D adiabatic 
equilibrium calculations (regardless of the height) in [9,17], respectively in $\mathrm{CH}_{4} /$ air and in $\mathrm{H}_{2} /$ air flames. These results indicate that the relative variation in the experimental density as function of the equivalence ratio was found in good agreement with the calculations. In the present work, several chemical mechanisms were tested in flame CH4(080) (Fig. S7) and all failed to describe the full shape of the O-atom profile. Also the discrepancy between the simulated profiles is within $15 \%$ at $\mathrm{HAB}=25 \mathrm{~mm}$. In absence of identified sources of experimental errors (like SE or photochemical or photolytic effects) at any location in the flames (especially in the flame front region), supplementary investigation for probing other species like $\mathrm{H}$ and $\mathrm{OH}$ are required to elucidate this point.

\section{Conclusions}

Two-photon LIF method has been applied to quantitatively measure the mole fraction of atomic oxygen in premixed low-pressure flames. The absolute calibration was performed for the first time in flames by using xenon according to the method proposed by Goehlich et al. [18]. Owing to a close spectral scheme of the excitation and collection of $\mathrm{O}$ and $\mathrm{Xe}$, it is indeed possible to convert the relative O-TPLIF signal in absolute mole fraction knowing the density of Xe injected in the premixed gases. The main difficulty arises from the determination of the quenching rates which are different between $\mathrm{O}$ and Xe. It appears that Xe is quenched much faster than O-atom, and the quenching rates of both species are lower in Ar than in $\mathrm{N}_{2}$. This is why a calibration flame diluted in $\mathrm{Ar}$ was stabilized at $2.8 \mathrm{kPa}$, where the fluorescence decay rate was directly measured.

After a direct quantification of O-atom in the flame diluted in Ar, the relative TPLIF signals collected in three low-pressure (5.3 $\mathrm{kPa}$ ) premixed $\mathrm{CH}_{4} / \mathrm{O}_{2} / \mathrm{N}_{2}$ flames (with equivalence ratios of $0.8,1.0,1.25$ ) have been converted to absolute mole fractions of $\mathrm{O}$-atom. The overall uncertainties were estimated to be around $45 \%$, mostly attributed to the ratio of the two-photon absorption cross-section (previously determined with an accuracy of $20 \%$ [20]). Nevertheless, the relative uncertainties are around $25 \%$ only. The absence of any interfering process (photochemical, photolytic, photoionization or SE...) was thoroughly controlled. The 
experimental O-atom profiles have been satisfyingly compared to the simulated ones using detailed kinetic mechanisms, revealing some features not yet captured by the models.

This first application of TPLIF calibration by using a noble gas is successfully demonstrated in lowpressure methane flames. Moreover, the novelty in the present work is that the calibration was performed directly in the flame, but not in a non-reactive mixture as reported in the plasma studies [16-20]. Thus, the resulting fluorescence from $\mathrm{Xe}$ and from $\mathrm{O}$-atom was obtained in exactly the same environment of pressure, temperature and colliders, contrary to what was previously performed. Thanks to the in situ measurements, the same experimental set-up was used, contrary to an indirect calibration performed in an adiabatic burner $[9,10,17]$. The main limitation of the procedure is the feasibility of the quenching rate measurements (being of the order of $10^{8} \mathrm{~s}^{-1}$ and higher). Therefore, it is expected that this method can be interestingly transposed at higher pressures by using fs-laser. However, such lasers being spectrally large, attention need to be paid while probing Xe or O particularly in the presence of interfering species such as NO.

\section{Acknowledgments}

This work is a contribution to the CPER research project CLIMIBIO. The authors thank the French Ministère de l'Enseignement Supérieur et de la Recherche, the Hauts-de-France Region and the European Funds for Regional Economical Development for their financial support to this project.

SMM.pdf file 


\section{References}

[1] J. Vandooren, M.C. Branch, P.J. Van Tiggelen, Comparisons of the structure of stoichiometric $\mathrm{CH}_{4}-\mathrm{N}_{2} \mathrm{O}-\mathrm{Ar}$ and $\mathrm{CH}_{4}-\mathrm{O}_{2}-\mathrm{Ar}$ flames by molecular beam sampling and mass spectrometric analysis, Combust. Flame. 90 (1992) 247-258.

[2] S. Cheskis, S.A. Kovalenko, Detection of atomic oxygen in flames by absorption spectroscopy, Appl. Phys. B. 59 (1994) 543-546. https://doi.org/10.1007/BF01082398.

[3] U. Meier, J. Bittner, K. Kohse-Höinghaus, T. Just, Discussion of two-photon laser-excited fluorescence as a method for quantitative detection of oxygen atoms in flames, Symp. Int. Combust. 22 (1989) 1887-1896. https://doi.org/10.1016/S0082-0784(89)80203-6.

[4] L. Gasnot, P. Desgroux, J.F. Pauwels, L.R. Sochet, Improvement of two-photon laser induced fluorescence measurements of $\mathrm{H}$ - and $\mathrm{O}$-atoms in premixed methane/air flames, Appl. Phys. B. 65 (1997) 639-646. https://doi.org/10.1007/s003400050326.

[5] J.E.M. Goldsmith, Photochemical effects in two-photon-excited fluorescence detection of atomic oxygen in flames, Appl. Opt. 26 (1987) 3566-3572. https://doi.org/10.1364/AO.26.003566.

[6] K.C. Smyth, P.J.H. Tjossem, Relative H-atom and O-atom concentration measurements in a laminar, methane/air diffusion flame, Symp. Int. Combust. 23 (1991) 1829-1837. https://doi.org/10.1016/S0082-0784(06)80463-7.

[7] D.L. van Oostendorp, H.B. Levinsky, C.E. van der Meij, R.A.A.M. Jacobs, W.T.A. Borghols, Avoidance of the photochemical production of oxygen atoms in one-dimensional, two-photon laser-induced fluorescence imaging, Appl. Opt. $32 \quad$ (1993) 4636-4640. https://doi.org/10.1364/AO.32.004636.

[8] J.H. Frank, X. Chen, B.D. Patterson, T.B. Settersten, Comparison of nanosecond and picosecond excitation for two-photon laser-induced fluorescence imaging of atomic oxygen in flames, Appl. Opt. 43 (2004) 2588-2597. https://doi.org/10.1364/AO.43.002588.

[9] W.D. Kulatilaka, S. Roy, N. Jiang, J.R. Gord, Photolytic-interference-free, femtosecond, twophoton laser-induced fluorescence imaging of atomic oxygen in flames, Appl. Phys. B Lasers Opt. 122 (2016) 1-7. https://doi.org/10.1007/s00340-016-6330-2.

[10] J.H. Frank, T.B. Settersten, Two-photon LIF imaging of atomic oxygen in flames with picosecond excitation, Proc. Combust. Inst. $30 \quad$ (2005) 1527-1534 https://doi.org/10.1016/j.proci.2004.08.151.

[11] J.B. Schmidt, B. Sands, J. Scofield, J.R. Gord, S. Roy, Comparison of femtosecond- and nanosecond-two-photon-absorption laser-induced fluorescence (TALIF) of atomic oxygen in atmospheric-pressure plasmas, Plasma Sources Sci. Technol. 26 (2017) 055004. https://doi.org/10.1088/1361-6595/aa61be.

[12] M. Aldén, J.E.M. Goldsmith, U. Westblom, Two-photon-excited stimulated emission from atomic oxygen in flames and cold gases, Opt. Lett. 14 (1989) 305-307. https://doi.org/10.1364/OL.14.000305.

[13] J.C. Miller, Two-photon resonant multiphoton ionization and stimulated emission in krypton and xenon, Phys. Rev. A. 40 (1989) 6969.

[14] A.D. Tserepi, E. Wurzberg, T.A. Miller, Two-photon-excited stimulated emission from atomic oxygen in rf plasmas: Detection and estimation of its threshold, Chem. Phys. Lett. 265 (1997) 297-302. https://doi.org/10.1016/S0009-2614(97)84252-2.

[15] S. Löhle, M. Auweter-Kurtz, Laser-Induced Fluorescence Measurements of Atomic Oxygen Using Two Calibration Methods, J. Thermophys. Heat Transf. 21 (2007) 623-629. https://doi.org/10.2514/1.26902.

[16] R.S. Barlow, G.J. Fiechtner, J.-Y. Chen, Oxygen atom concentrations and NO production rates in a turbulent $\mathrm{H} 2 / \mathrm{N} 2$ jet flame, Symp. Int. Combust. 26 (1996) 2199-2205 https://doi.org/10.1016/S0082-0784(96)80046-4. 
[17] K.A. Rahman, V. Athmanathan, M.N. Slipchenko, S. Roy, J.R. Gord, Z. Zhang, T.R. Meyer, Quantitative femtosecond, two-photon laser-induced fluorescence of atomic oxygen in highpressure flames, Appl. Opt. 58 (2019) 1984-1990. https://doi.org/10.1364/AO.58.001984.

[18] A. Goehlich, T. Kawetzki, H.F. Döbele, On absolute calibration with xenon of laser diagnostic methods based on two-photon absorption, J. Chem. Phys. 108 (1998) 9362-9370.

[19] H.F. Döbele, T. Mosbach, K. Niemi, V. Schulz von der Gathen, Laser-induced fluorescence measurements of absolute atomic densities: concepts and limitations, Plasma Sources Sci. Technol. 14 (2005) S31-S41.

[20] K. Niemi, V. Schulz von der Gathen, H.F. Döbele, Absolute atomic oxygen density measurements by two-photon absorption laser-induced fluorescence spectroscopy in an RFexcited atmospheric pressure plasma jet, Plasma Sources Sci. Technol. 14 (2005) 375-386.

[21] G.D. Stancu, F. Kaddouri, D.A. Lacoste, C.O. Laux, Atmospheric pressure plasma diagnostics by OES, CRDS and TALIF, J. Phys. Appl. Phys. $43 \quad$ (2010) 124002 https://doi.org/10.1088/0022-3727/43/12/124002.

[22] A.F.H. van Gessel, S.C. van Grootel, P.J. Bruggeman, Atomic oxygen TALIF measurements in an atmospheric-pressure microwave plasma jet with in situ xenon calibration, Plasma Sources Sci. Technol. 22 (2013) 055010.

[23] N. Lamoureux, H. El Merhubi, L. Pillier, S. de Persis, P. Desgroux, Modeling of NO formation in low pressure premixed flames, Combust. Flame. 163 (2016) 557-575. http://dx.doi.org/10.1016/j.combustflame.2015.11.007.

[24] R.J. Kee, F.M. Rupley, J.A. Miller, CHEMKIN-II: A Fortran Chemical Kinetics Package for the Analysis of Gas-Phase Chemical, Sandia National Laboratories, Livermore, 1989.

[25] N. Lamoureux, P. Desgroux, A. El Bakali, J.F. Pauwels, Experimental and numerical study of the role of NCN in prompt-NO formation in low-pressure $\mathrm{CH}_{4} / \mathrm{O}_{2} / \mathrm{N}_{2}$ and $\mathrm{C}_{2} \mathrm{H}_{2} / \mathrm{O}_{2} / \mathrm{N}_{2}$ flames, Combust. Flame. 157 (2010) 1929-1941.

[26] M.D. Sylla, N. Lamoureux, L. Gasnot, Impact of methyl butanoate oxidation on NO formation in laminar low pressure flames, Fuel. 207 (2017) 801-813 https://doi.org/10.1016/j.fuel.2017.06.029.

[27] A. Kramida, Y. Ralchenko, J. Reader, NIST ASD Team, NIST Atomic Spectra Database (version 5.7.1), Https://Physics.Nist.Gov/Asd. (2019). https://physics.nist.gov/asd.

[28] R.P. Saxon, J. Eichler, Theoretical calculation of two-photon absorption cross sections in atomic oxygen, Phys. Rev. A. 34 (1986) 199-206.

[29] M. Aymar, M. Coulombe, Theoretical transition probabilities and lifetimes in Kr I and Xe I spectra, At. Data Nucl. Data Tables. 21 (1978) 537-566. https://doi.org/10.1016/0092640X(78)90007-4.

[30] J. Bittner, K. Kohse-höinghaus, U. Meier, Th. Just, Quenching of two-photon-excited H(3s, 3d) and $\mathrm{O}(3 \mathrm{p} 3 \mathrm{P} 2,1,0)$ atoms by rare gases and small molecules, Chem. Phys. Lett. 143 (1988) 571576. https://doi.org/10.1016/0009-2614(88)87068-4.

[31] T.I. Quickenden, S.M. Trotman, J.A. Irvin, D.F. Sangster, H2O quenching of the transitions $\mathrm{H}(\mathrm{n}=3 \rightarrow \mathrm{n}=2)$ and $\mathrm{O}(3 \mathrm{p} 3 \mathrm{P} \rightarrow 3 \mathrm{~s} 3 \mathrm{~S} 0)$ in pulse radiolytically excited water vapor, J. Chem. Phys. 71 (1979) 497-501. https://doi.org/10.1063/1.438067.

[32] V. Alekseev, D.W. Setser, Quenching Rate Constants and Product Assignments for Reactions of $\mathrm{Xe}(7 \mathrm{p}[3 / 2] 2,7 \mathrm{p}[5 / 2] 2$, and 6p' [3/2]2) Atoms with Rare Gases, CO, H2, N2O, CH4, and HalogenContaining Molecules, J. Phys. Chem. 100 (1996) 5766-5780. https://doi.org/10.1021/jp952402c. 


\section{List of figure captions}

Fig. 1. TPLIF excitation and collection schemes of atomic $\mathrm{O}$ and $\mathrm{Xe}$, from NIST [27]. The transition wavelengths are in vacuum.

Fig. 2. Stern-Volmer plot for Xe at room temperature and in the burned gases of flame CH4_cal.

Fig. 3. TPLIF quadratic regime for $\mathrm{O}$ and $\mathrm{Xe}$. Solid lines represent the limit in which the quadratic regime is verified, and the dashed lines are extrapolated from the linear fit. For clarity, the TPLIF signal of O-atom in flame $\mathrm{CH} 4$ cal is divided by 2.

Fig. 4. O-atom mole fraction, temperature and fluorescence decay rate $(\mathrm{A}+\mathrm{Q})$ profiles along the $\mathrm{HAB}$ of flame CH4_cal.

Fig. 5. Stern-Volmer plot for O-atom in flames.

Fig. 6. O-atom mole fraction profiles in flames diluted with $\mathrm{N}_{2}$. Symbols: experimental points, lines: simulated with NOMecha2.0 [23]. 